\title{
DENTAL PROSTHESIS; DENTAL PROSTHESIS FOR CLEFT PATIENT FOR ACHIEVEMENT OF RETENTION
}

1. BDS, FCPS

Associate Professor \& Head Department of Prosthodontics, Hamdard College of Medicine \& Dentistry, Karachi.

2. BDS, MCPS

Assistant Professor \& Head Department of Community Dentistry Nishtar Institute of Dentistry, Multan.

3. BDS, MSc

Professor \& Head

Department of Oral Pathology, Hamdard College of Medicine \& Dentistry, Karachi.

4. BDS, MSc Lecturer Department of Prosthodontics, Hamdard College of Medicine \& Dentistry, Karachi.

Correspondence Address:

Dr Mehmood Hussain

House No: A- 695, Block H,

Northnazimabad, Karachi.

mhussain26@hotmail.com

Article received on:

28/02/2017

Accepted for publication:

16/04/2017

Received after proof reading: 06/05/2017

\section{INTRODUCTION}

Achievement of retention in obturators for cleft patients is a real big challenge for Prosthodontist. Various methods or techniques can be employed to get adequate mechanical qualities in dental prosthesis to restore functional abilities \& esthetics for cleft patients. ${ }^{1}$

Using fundamental principles for achieving retention in any prosthesis, various important factors like edentulous span, condition of existing dentition with special focus on abutment teeth, periodontal status, extent of the defect, lip line, smile line, age \& socioeconomic status of the patient should be kept in mind during treatment planning phase. ${ }^{2}$

During provision of removable partial denture study was carried out at Hamc

\section{Dr. Mehmood Hussain', Dr. Muhammad Imran Bucha², Dr. Tahir Ali ${ }^{3}$, Dr. Moin Khan ${ }^{4}$} was three years. Materials and Methods: Total 30 patients were selected after taking consent random sampling technique. The age range varies from 01 month to 45 years. Among 30 , 19 were female while 11 were males. Special designed Performa was made and filled ( utilizing various method of retention. Results: Feeding plate was fabricated for five patients number of clasp is incorporated To get better patient's compliance flexible removable partial denture was fabricated for 03 patients while precision attachment was provided to one patient. Speech bulb prosthesis was fabricated for one patient, its retention was mainly achieved by means of Adam's clasp. Seven patients were provided with fixed prosthesis, in four cases pink provided to any patient. Conclusion: Utilization of various means of retention brings better

Key words: $\quad$ Cleft patient, dentures, prosthodontist, obturators.

Article Citation: Hussian M, Bucha MI, Ali T, Khan M. Dental prosthesis; dental prosthesis for cleft patient for achievement of retention. Professional Med J 2017;24(5):767771.DOI: 10.17957/TPMJ/17.3853

(RPD), designing of the prosthesis is very important. Correct selection of clasp is very critical step, which itself depend upon multiple factors. When necessary, one must incorporate indirect retainer in the prosthesis as well. Harmonious occlusion \& extension of the prosthesis within the physiological limits are also helpful in getting retention. ${ }^{3,4}$

Though rare but still there are few edentulous patients having cleft as well, for them all basis principles to get retention in complete denture should be utilized with special focus on coverage of prosthesis up to the defect part in order to improve speech \& swallowing. ${ }^{5}$

Accomplishment of retention in fixed prosthesis is dependent upon the condition of abutment tooth, 
crown root ratio, extension of edentulous span, type of luting agent, periodontal status. ${ }^{6}$

With recent advances, now implant supported prosthesis are also provided for cleft patients but still their usage \& data regarding longevity of the prosthesis is still limited. ${ }^{7}$

Apart from conventional means of retention, various gadgets like magnets, precision attachment, and hinge mechanism can also be used to achieve retention in dental prosthesis for cleft patients. $^{8}$

In this article, provision of various methods \& techniques to get retention in prosthesis fabricated for cleft patients is discussed.

\section{MATERIAL \& METHOD}

It was a descriptive study and conducted at Prosthodontics Department of Hamdard University Dental Hospital, Karachi. The duration of this study was three years, in total 30 patients were selected after taking consent by random sampling technique. The age range varies from 01 month to 45 years. Among 30 patients, 19 were female while 11 were males. Special designed Performa was made and filled by getting all related information from patient/ attendants. Then various treatment options were discussed with the patient or attendant \& with mutual consent prosthesis was fabricated utilizing various method of retention.

\section{RESULTS}

Prosthetic Rehabilitation was provided by means of fabrication of different types of prosthesis. Feeding plate was fabricated for five patients, in which retention is achieved through maximum extension of prosthesis, using elastic band, utilization of favorable undercuts.

Conventional removable partial denture was fabricated for 17 patients. Among those 17 patients, cast partial denture (CPD) was fabricated for eight patients, while in one patient of CPD precision attachments were also incorporated. For 06 patients acrylic removable denture was fabricated. Mainly retention was achieved through retainers, considering esthetics maximum number of clasp is incorporated. Apart from clasp, special focus will be on maximum extension of the prosthesis within the physiological limit in order to get more retention To get better patient's compliance flexible removable partial denture was fabricated for 03 patients while precision attachment was provided to one patient.

Speech bulb prosthesis was fabricated for one patient, its retention was mainly achieved by means of Adam's clasp.

Seven patients were provided with fixed prosthesis, along with utilization of basic principles of retention in fixed prosthesis, in four cases pink porcelain was added in cervical area to further improve esthetics \& retention.

Mainly due to financial status \& poor compliance from the patients, implant supported prosthesis was not provided to any patient.

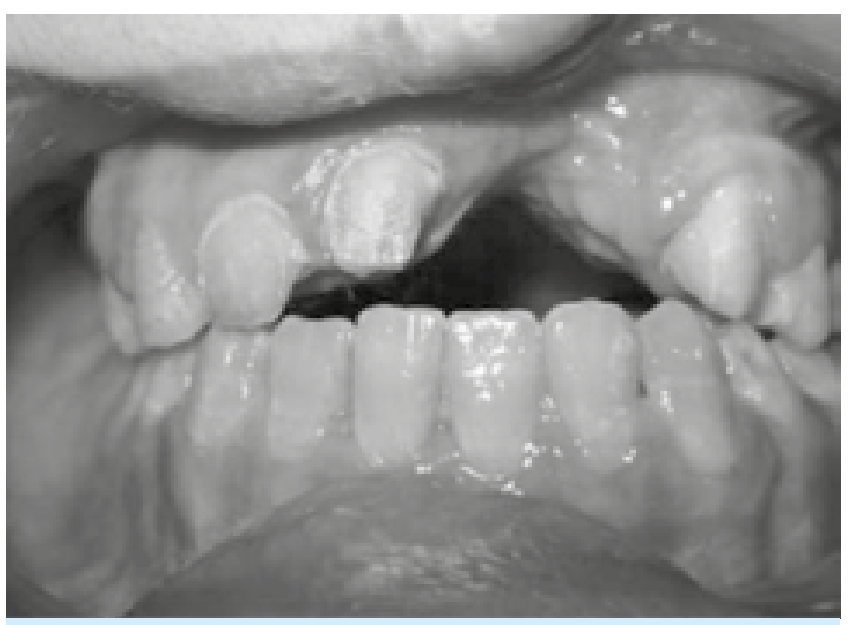

Figure-1. Intra Oral view of Cleft Defect

\section{DISCUSSION}

Oral rehabilitation for cleft patients starts from very early age. By fabrication of feeding plates for neonates, functions like suckling \& swallowing will be markedly improved. ${ }^{9}$

In this study feeding obturators were fabricated for five patients, retention was mainly achieved by utilization of favorable undercuts. Use of certain innovations like using elastic band extra orally also helps in retention of the feeding plate. ${ }^{10}$ 


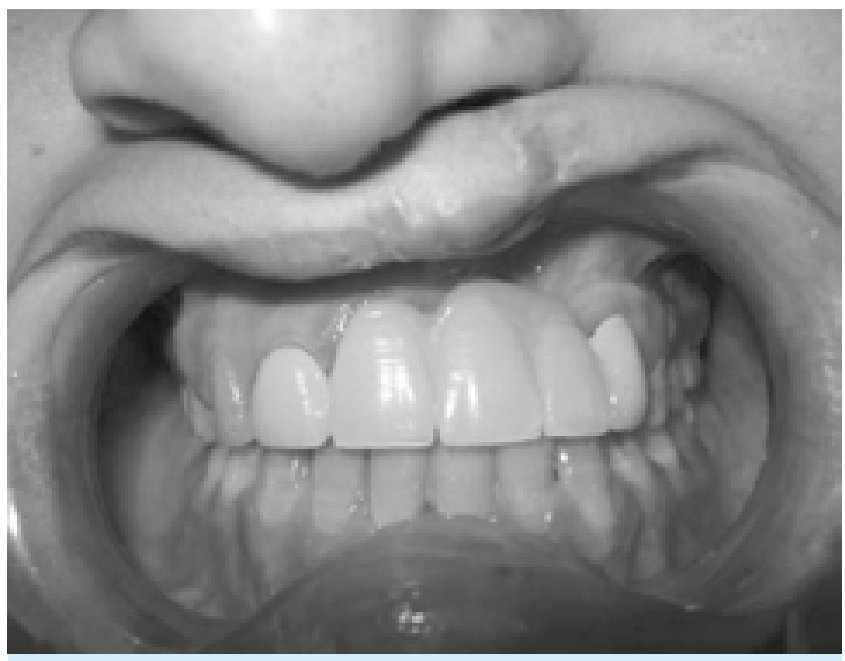

Figure-2. Provision of Fixed Prosthesis with pink porcelain

In this study (RPD) were provided for 17 patients, primarily clasp is the main source of retention for patients wearing RPD. Selection of particular type of clasp depends upon the extension of defect, abutmenttooth status, presence of favorable under cut \& periodontal status. Maximum extension of the prosthesis within the physiological limit also assists in getting retention. In this study this rule is applied for all patients. It was noted that there was marked improvement in functional capacity \& esthetic out come in cleft patients after provision of RPD having adequate retention. Adusumili et al discussed a case in which cleft patient was provided with RPD \& satisfactory results were obtained. ${ }^{12}$

For further enhancement in esthetics \& retention for cleft patients, provision of RPD by means of various types of attachments is a very useful option. In this study precision attachment was provided to one patient. Palmeiro et $\mathrm{al}^{13}$ also discussed a case where RPD was provided along with attachment to the cleft patient.

For three patients in this study, flexible partial denture was fabricated, this will not only improve their esthetics but also improve the retention in the prosthesis by better adaptation as compare to conventional acrylic removable partial denture. Thirumurthy et al also discussed a case where removable flexible partial denture was fabricated for cleft patient. ${ }^{14}$

Speech bulb prosthesis was also fabricated for one patient having soft palate cleft, in which retention was obtained mainly means of Adam's clasp on both sides. Yenisey et al also discussed a case report where speech bulb prosthesis was fabricated and good results were obtained. ${ }^{15}$

Fixed prosthesis was provided for seven patients, retention was mainly achieved through prepared abutment teeth \& luting agent. Apart from improvement in esthetics \& functional abilities, the psychological impact of these patients was also markedly enhanced after provision of fixed prosthesis. Canapolat et $\mathrm{al}^{16}$ observed better results after provision of fixed prosthesis for cleft patients. All patients were satisfied with their fixed prosthesis \& there was no case of decementation till six months. Bidra also discussed a case report where conventional fixed prosthesis was fabricated for cleft patient. ${ }^{17}$

In this study, pink porcelain was incorporated in the cervical area of fixed prosthesis in order to get better esthetics \& retention as shown in figure $1 \& 2$. Small also reported the use of pink porcelain in fixed prosthesis. ${ }^{18}$

For better retention, if feasible then provide orthodontic treatment prior to fabricate any prosthesis where necessary. In this study three patients underwent orthodontic treatment. Then after completion of their orthodontic treatment, fixed prosthesis was provided for two patients while RPD was fabricated for one patient. Conley discussed a case where orthodontic treatment was conducted prior to prosthesis fabrication in cleft patient for better outcome. ${ }^{19}$

Jaija et $\mathrm{al}^{20}$ in their study, conducted in Pakistani population reported that cleft patients reported to health care provider very late. There is poor post-surgical follow up and also there was lack of awareness regarding in health care provider \& parents of cleft patients for their timely rehabilitation. 
There is an immense need that in our country, special programs will be arranged for parents of cleft patients \& health care provider to increase the awareness and knowledge about dental prosthesis. When patients will reach Prosthodontist at an early stage, then it is comparatively easier to fabricate dental prosthesis having good retention.

\section{CONCLUSION}

Presence of retention is the primary requisite for the success of any dental prosthesis. Retention can be achieved by means of various methods or techniques, which should be utilized by Prosthodontist wisely for oral rehabilitation of cleft patients.

\section{Copyright@ 16 Apr, 2017.}

\section{REFERENCES}

1. Goiato MC, dos Santos DM, Moreno A, Santiago JF Jr, Haddad MF, Pesqueira AA, Miyahara GI. Prosthetic treatments for patients with oronasal communication. J Craniofac Surg 2011; 22: 1445-47.

2. Burnett CA, Clifford TJ. Prosthodontic rehabilitation of patients with orofacial defects. Dent Update 2012; 39: 291-96.

3. Balkaya MC, Sultan H, Erdem S, Mutlu D. Prosthetic rehabilitation of a patient with a unilateral cleft palate: a clinical report. J Prosthet Dent 2014; 111: 269-72.

4. Palmeiro MR, Piffer CS, Brunetto VM, Maccari PC, Shinkai RS. Maxillary rehabilitation using a removable partial denture with attachments in a cleft lip and palate patient: a clinical report. $J$ Prosthodont 2015; 24: 250-53.

5. Sarmento HR, Rodigues PB, Marcello-Machado RM, Pinto LR, Faot F. Prosthetic rehabilitation of an edentulous patient with cleft palate. Gen Dent 2014; 62: 32-35.

6. Ahmed B, Hussain M, Butt AM, Yazdanie N. Maxillofacial rehabilitation of a large cleft palate using fixedremovable prosthesis. J Coll Physicians Surg Pak 2011; 21: 52-54.

7. Sedlackova K, Duskova $M$, Strnadel $T$, Kotova $M$, Haas $M$. Using dental implants in the prosthetic rehabilitation of patients with cleft defect type II. Cleft Palate Craniofac J 2011; 48: 98-102.

8. Goiato MC, dos Santos DM, Moreno A, Santiago JF Jr, Haddad MF, Pesqueira AA, Miyahara GI. Prosthetic treatments for patients with oronasal communication.
J Craniofac Surg 2011; 22: 1445-47.

9. Wells M. Oral health status of children with craniofacial anomalies. Pediatr Dent 2013; 35: 79-86.

10. Goyal M, Chopra R, Bansal K, Marwaha M. Role of obturators and other feeding interventions in patients with cleft lip and palate: a review. Eur Arch Paediatr Dent 2014; 15: 1-9.

11. Bansal R, Kumar Pathak A, Bhatia B, Gupta S, Kumar Gautam K. Rehabilitation of a One-day-Old Neonate with Cleft Lip and Palate using Palatal Obturator: A Case Report. Int J Clin Pediatr Dent 2012; 5: 145-47.

12. Adusumilli SP, Sudhakar P, Mummidi B, Reddy KV, Rao $\mathrm{CH}$, Raju $\mathrm{BH}$. Interdisciplinary treatment of an adolescent with unilateral cleft lip and palate. J Contemp Dent Pract 2013; 14: 332-38.

13. Palmeiro MR, Piffer CS, Brunetto VM, Maccari PC, Shinkai RS. Maxillary rehabilitation using a removable partial denture with attachments in a cleft lip and palate patient: a clinical report. $J$ Prosthodont 2015; 24: 250-53.

14. Thirumurthy VR, Bindhoo YA, Jacob SJ, Kurien A, Limson KS. Prosthetic rehabilitation of postsurgical nasomaxillary hypoplasia for a patient following reconstructive surgery: a clinical report. J Prosthodont 2011; 20: 224-27.

15. Yenisey M, Cengiz S, Sarıkaya I. Prosthetic treatment of congenital hard and soft palate defects. Cleft Palate Craniofac J 2012; 49: 618-21.

16. Canpolat C, Özkurt-Kayahan Z, Kazazoğlu E. Prosthetic rehabilitation of maxillary dentoalveolar defects with fixed dental prostheses: two clinical reports. J Prosthet Dent 2014; 112: 418-22.

17. Bidra AS. Esthetic and functional rehabilitation of a bilateral cleft palate patient with fixed prosthodontic therapy. J Esthet Restor Dent 2012; 24: 236 - 44.

18. Small BW. The use of pink porcelain for gingival defects in restorative dentistry: a case report. Gen Dent 2010; 58: 285-87.

19. Ma QL, Conley RS, Wu T, Li H. Interdisciplinary treatment for an adult with a unilateral cleft lip and palate. Am J Orthod Dentofacial Orthop 2014; 146: 238- 48.

20. Jajja MR, Gilani A, Cawasji ZF, Imran S, Khan MS, Hashmi SS, Khan TS. Oral clefts: a review of the cases and our experience at a single institution. $J$ Pak Med Assoc 2013; 63: 1098-102. 

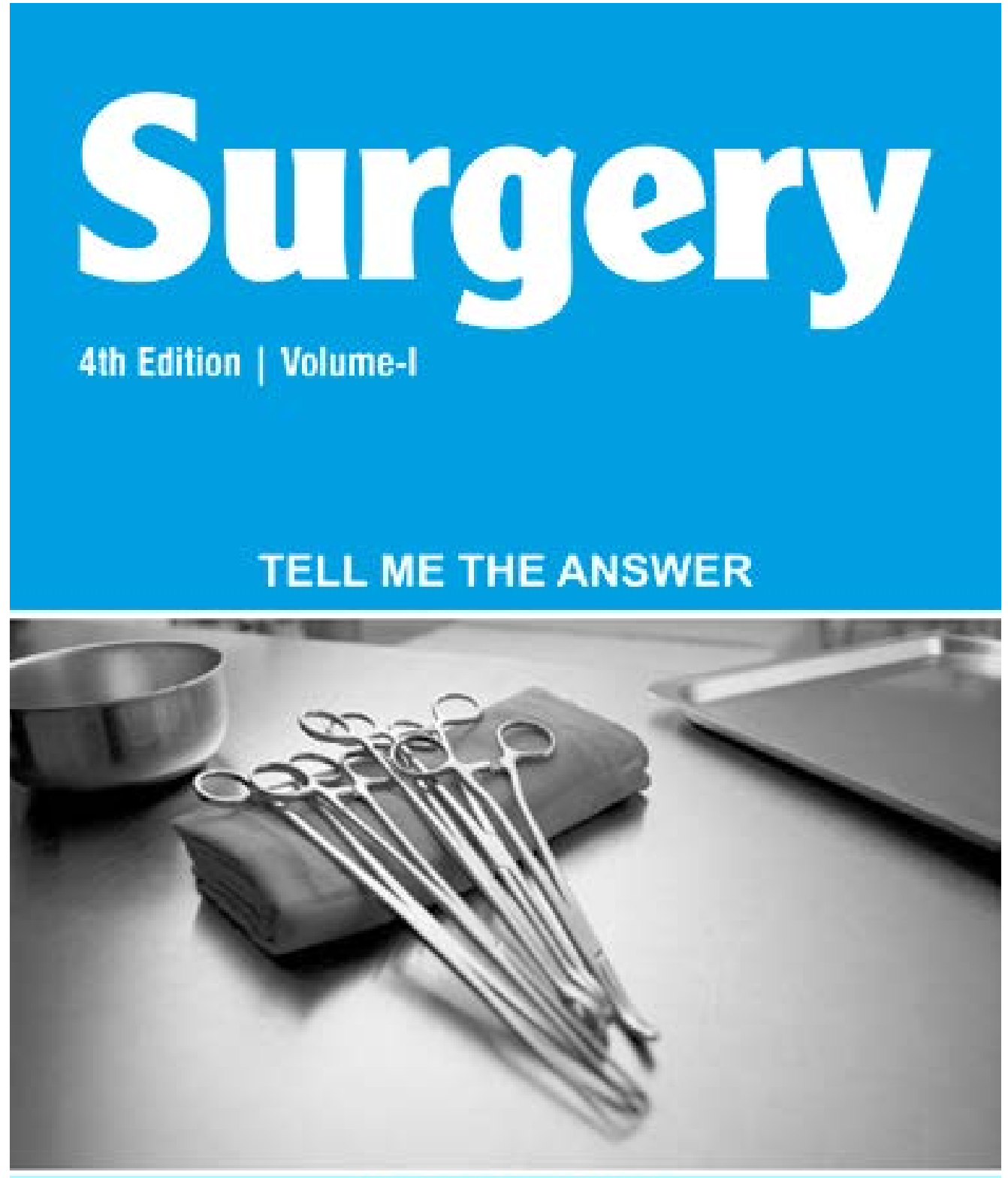

Muhammad Shuja Tahir

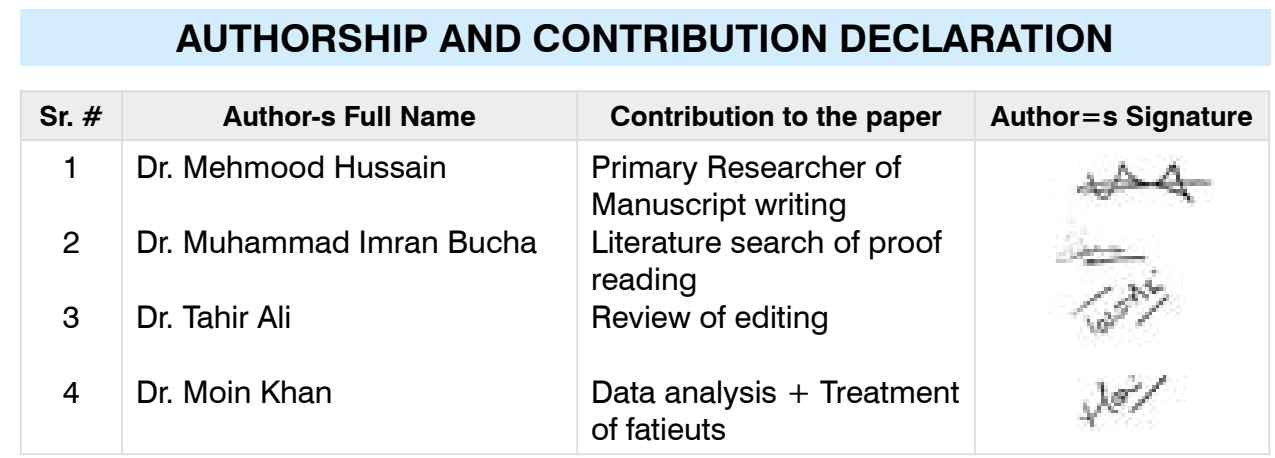

